\title{
Women are different: the role of coupling factor 6 in blood pressure regulation
}

\author{
Lisandra E de Castro Brás, Kristine Y DeLeon and Merry L Lindsey \\ Hypertension Research (2012) 35, 485-486; doi:10.1038/hr.2012.9; published online 2 February 2012
}

$\mathrm{B}^{1}$ lood pressure (BP)-related diseases, particularly, hypertension, coronary heart disease, heart failure and stroke are the leading causes of morbidity and mortality. Worldwide, elevated BP accounts for $47 \%$ of coronary heart disease cases and $54 \%$ of stroke incidences. ${ }^{1}$ Moreover, about $13 \%$ of total deaths worldwide are a result of hypertension. The excessive intake of salt has a major role in the pathogenesis of hypertension. To date, over 50 randomized trials have tested the effects of sodium reduction on BP in adults, with the overall consensus that sodium intake has a statistically significant, progressive and dose-dependent relationship with BP. A daily modest reduction of $100 \mathrm{mmol}$ ( $6 \mathrm{~g}$ of salt) has been shown to significantly reduce systolic and diastolic BP in both the hypertensive and normotensive subjects. $^{2}$ In this issue of Hypertension Research, Izumiyama et al. ${ }^{3}$ show that estrogen replacement has a cardioprotective function in ovariectomized females under a highsalt diet (HSD). Furthermore, they report on the mechanism whereby coupling factor 6 (CF6) overexpression increases salt-sensitive hypertension, resulting in enhanced cardiac systolic dysfunction.

The National Health and Nutrition Examination Survey showed that more men than women have hypertension until 45 years of age. ${ }^{4}$ The prevalence and severity of hypertension upsurges significantly with age in women, such that more women than men

Dr L de Castro Brás, Dr KY DeLeon and Dr ML Lindsey are at the NHLBI Cardiovascular Proteomics Center, University of Texas Health Science Center, 15355 Lambda Drive, MC 7755, San Antonio, TX 78245 USA. Barshop Institute of Longevity and Aging Studies and Department of Medicine, Division of Geriatrics, Gerontology and Palliative Medicine, University of Texas Health Science Center, 15355 Lambda Drive, MC 7755, San Antonio, TX 78245, USA.

E-mail: lindseym@uthscsa.edu are hypertensive after 65 years of age.,5 Izumiyama et al. show that male transgenic mice overexpressing CF6 (TG) develop hypertension sooner than females when fed HSD. Although TG males showed increased systolic BP beginning at 20 weeks of HSD, it was not until 60 weeks of HSD that the TG females demonstrated elevated systolic BP. Interestingly, wild-type mice, both male and female, did not show hypertension when fed HSD.

In a second experiment, ovariectomized young TG females were treated with estrogen replacement $(0.18 \mathrm{mg}$ estradiol) or placebo, 1 week post-surgery under HSD. They showed a marked increase in systolic BP of TG mice that were ovariectomized, compared with animals that underwent sham surgery. In addition, left ventricular fractional shortening, a measurement of cardiac function, decreased in ovariectomized females, but this effect was not observed when ovariectomized females received estrogen replacement. A European study for diagnosis of hypertension showed that the prevalence of hypertension in postmenopausal women was more than twice that in premenopausal women. ${ }^{6}$ These findings suggest that changes in ovarian hormone levels are related to changes in BP. Izumiyama et al. results are in agreement with these findings. Over the last 30 years, many studies involving BP and hormone replacement therapy have been conducted, but the findings have been inconsistent. In normotensive women treated with hormone replacement therapy, BP has been shown to decrease, ${ }^{7}$ increase $^{8}$ or remain unaffected. ${ }^{9}$ A study comprising 809 postmenopausal women with and without hysterectomy did not show an association between hysterectomy and increased risk of cardiovascular disease (CVD). ${ }^{10}$ Contrarily, a Women's Health Initiative observational study com- pared CVD risk factors between postmenopausal women who had and had not undergone hysterectomy, with or without ovariectomy, in a total of 89914 patients. ${ }^{11}$ They concluded that women with a hysterectomy had a worse risk profile and higher prevalence and incidence of CVD. Nevertheless, they also reported that multivariate models suggested that CVD risks were rather due to the more adverse initial risk profile of women who had undergone hysterectomy, and not that hysterectomy was the major determinant for CVD. ${ }^{11}$

In the Izumiyama study, CF6 TG mice showed elevated levels of activated Rac1, a member of the Rho family GTPases, leading to salt-sensitive hypertension. ${ }^{3}$ CF6 is a component of the intrinsic membrane domain $\left(\mathrm{F}_{0}\right)$ of ATP synthase, which is considered to be essential for energy transduction. ${ }^{12}$ Recently CF6 has been identified to have multiple extracellular roles as a circulating hormone. ${ }^{12}$ CF6 increases arterial BP in rats, which is consistent with high levels of CF6 seen in the plasma of patients diagnosed with hypertension. ${ }^{13}$ Studies where CF6 is quantified in pre or postmenopausal women, however, have not been carried out. CF6 functions are believed to be mediated by binding to the plasma membrane-bound ATP synthase, ecto- $\mathrm{F}_{1} \mathrm{~F}_{0}$ complex, resulting in proton import and acidosis, which will in turn increase activated Rac1. Although the authors show a correlation between estrogen and Racl activation, the exact mechanism was not explored. In recent studies, cardiac-specific overexpression of constitutively activated Rac1-induced atrial fibrillation in mice via activation of the superoxide-producing NADPH-oxidase, indicating the importance of Rac1 in reactive oxygen species (ROS) production. ${ }^{14}$ A decrease of Racl expression by estrogen was completely blocked in the 


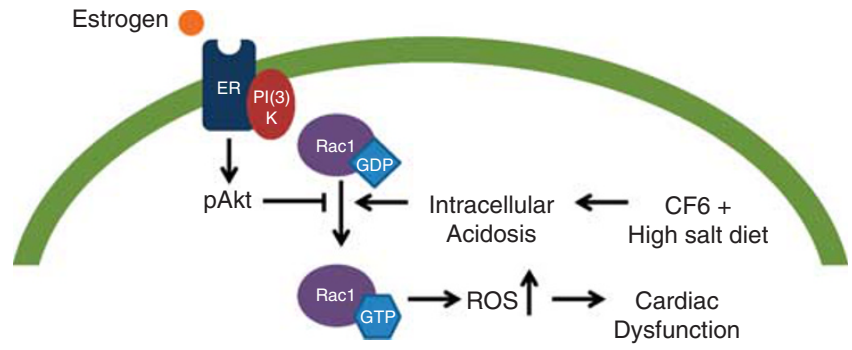

Figure $1 \mathrm{~A}$ high-salt diet can increase intracellular acidosis through CF6 proton import; acidosis then stimulates Rac 1 and increases reactive oxygen species (ROS) formation. Increased ROS can lead to cardiac dysfunction. In the presence of estrogen, the estrogen receptor (ER) can bind to the regulatory subunit, p85a, of phosphatidylinositol-3-OH kinase $(\mathrm{PI}(3) \mathrm{K})$, inducing enhanced activation of Akt. Akt is involved in cellular survival pathways, by inhibiting apoptotic processes and activated Akt can phosphorylate Rac1 at Ser71 reducing Rac1 activation. This in turn would reduce ROS-induced injury to the cardiovascular system as well as lower salt retention.

presence of a nonselective estrogen receptor (ER) antagonist, suggesting a receptormediated event. $^{15}$ Ex vivo studies have shown that ER can bind to the regulatory subunit, p85a, of phosphatidylinositol-3-OH kinase leading to enhanced activation of Akt in the presence of estrogen. ${ }^{16}$ Akt is involved in cellular survival pathways, by inhibiting apoptotic processes and activated Akt can phosphorylate Racl at Ser71 reducing Rac1 activation. ${ }^{17}$ This in turn would reduce ROSinduced injury to the cardiovascular system as well as lower salt retention (Figure 1). Although Izumiyama et al. showed that estrogen replacement, in ovariectomized mice, would decrease the activation of Rac1, no connection with Akt was evaluated. Further in vivo studies would be needed in order to validate the decrease in activated Racl to be due to activation of Akt.

The effect of menopause on hypertension is controversial, masked by the effects of aging and clusters of other CVD risk factors, such as body weight and lipid levels. Further, studies have shown that with age cardiac extracellular matrix accumulates to induce a modest cardiac dysfunction. ${ }^{18}$ Whether estrogen replacement has a role in protecting from cardiac extracellular matrix accumulation in postmenopausal females would provide additional insight into this complex issue. The study by Izumiyama et al. emphasizes the usefulness of mice models; by using transgenic mice overexpressing CF6 to establish a connection between CF6 levels and salt-sensitive hypertension. In summary, Dr Izumiyama et al. provide further support for the concept that hormone replacement, given during the postmenopausal period, mitigates adverse cardiac effects caused by increased levels of activated Racl.

\section{ACKNOWLEDGEMENTS}

We acknowledge support from the NIH NHLBI T32 HL07446 to KYD; and from the NHLBI HHSN 268201000036C (N01-HV-00244) for the UTHSCSA Cardiovascular Proteomics Center and R01 HL075360, the Max and Minnie Tomerlin Voelcker Fund, and the Veteran's Administration (Merit) to MLL.

1 Lawes CM, Vander Hoorn S, Rodgers A. Global burden of blood-pressure-related disease, 2001. Lancet 2008;

2 He FJ, Marciniak M, Visagie E, Markandu ND, Anand V, Dalton RN, MacGregor GA. Effect of modest salt reduction on blood pressure, urinary albumin, and pulse wave velocity in white, black, and Asian mild hypertensives. Hypertension 2009; 54: 482-488.

3 Izumiyama K, Osanai T, Sagara S, Yamamoto Y, Itoh T, Sukekawa T, Nishizaki F, Magota K, Okumura K. Estrogen attenuates coupling factor 6 -induced salt-sensitive hypertension and cardiac systolic dysfunction in mice. Hypertens Res 2012; 35: 539-546.

4 Ong KL, Tso AW, Lam KS, Cheung BM. Gender difference in blood pressure control and cardiovascular risk 371: 1513-1518. factors in Americans with diagnosed hypertension. Hypertension 2008; 51: 1142-1148.

5 Wassertheil-Smoller S, Hendrix SL, Limacher M, Heiss G, Kooperberg C, Baird A, Kotchen T, Curb JD, Black H, Rossouw JE, Aragaki A, Safford M, Stein E, Laowattana S, Mysiw WJ. Effect of estrogen plus progestin on stroke in postmenopausal women: the Women's Health Initiative: a randomized trial. JAMA 2003; 289: 2673-2684.

6 Staessen J, Bulpitt CJ, Fagard R, Lijnen P, Amery A. The influence of menopause on blood pressure. J Hum Hypertens 1989; 3: 427-433.

7 Butkevich A, Abraham C, Phillips RA. Hormone replacement therapy and 24-hour blood pressure profile of postmenopausal women. Am J Hypertens 2000; 13: 1039-1041.

8 Wren BG, Routledge DA. Blood pressure changes: oestrogens in climacteric women. Med J Aust 1981; 2: 528-531.

9 Pripp U, Hall G, Csemiczky G, Eksborg S, Landgren BM, Schenck-Gustafsson K. A randomized trial on effects of hormone therapy on ambulatory blood pressure and lipoprotein levels in women with coronary artery disease. J Hypertens 1999; 17: 1379-1386.

10 Fletcher HM, Bennett F, Simms-Stewart D, Reid M, Williams NP, Wharfe GH, Wilks RJ, Mitchell S, Scott P. Cardiovascular disease risk factors in menopausal Jamaican black women after hysterectomy and bilateral oophorectomy: an observational study. West Indian Med J 2010; 59: 625-632.

11 Howard BV, Kuller L, Langer R, Manson JE, Allen C, Assaf A, Cochrane BB, Larson JC, Lasser N, Rainford M, Van Horn L, Stefanick ML, Trevisan M. Risk of cardiovascular disease by hysterectomy status, with and without oophorectomy-The Women's Health Initiative Observational Study. Circulation 2005; 111: 1462-1470.

12 Osanai T, Tanaka M, Kamada T, Nakano T, Takahashi K, Okada S, Sirato K, Magota K, Kodama S, Okumura K. Mitochondrial coupling factor 6 as a potent endogenous vasoconstrictor. J Clin Invest 2001; 108: 1023-1030.

13 Osanai T, Saitoh M, Sasaki S, Tomita H, Matsunaga T, Okumura K. Effect of shear stress on asymmetric dimethylarginine release from vascular endothelial cells. Hypertension 2003; 42: 985-990.

14 Adam O, Frost G, Custodis F, Sussman MA, Schafers HJ, Bohm M, Laufs U. Role of Rac1 GTPase activation in atrial fibrillation. J Am Coll Cardiol 2007; 50: 359-367.

15 Adam O, Hagel M, Theobald K, Bohm M, Laufs U. Inhibitory effect of estrogen on Racl-expression in monocytes. Biochem Biophys Res Commun 2009; 386: 45-49.

16 Simoncini T, Hafezl-Moghadam A, Brazil DP, Ley K, Chin WW, Liao JK. Interaction of oestrogen receptor with the regulatory subunit of phosphatidylinositol-3$\mathrm{OH}$ kinase. Nature 2000; 407: 538-541.

17 Zhang QG, Raz L, Wang RM, Han D, De Sevilla L, Yang F, Vadlamudi RK, Brann DW. Estrogen attenuates ischemic oxidative damage via an estrogen receptor alpha-mediated inhibition of NADPH oxidase activation. J Neurosci 2009; 29: 13823-13836.

18 Chiao YA, Dai Q, Zhang J, Lin J, Lopez EF, Ahuja SS, Chou YM, Lindsey ML, Jin YF. Multi-analyte profiling reveals matrix metalloproteinase- 9 and monocyte chemotactic protein-1 as plasma biomarkers of cardiac aging. Circ Cardiovasc Genet 2011; 4: 455-462. 